\title{
On the Aesthetic Cognition Connotation for $A$ Bite of China: Cultural Identity Space Shaped by the Media
}

\author{
Yuan Li \\ College of Chinese Language \& Literature, China West Normal University, Nanchong, China \\ Email: 70544424@qq.com
}

Received 21 July 2016; accepted 14 August 2016; published 17 August 2016

Copyright (C) 2016 by author and Scientific Research Publishing Inc. This work is licensed under the Creative Commons Attribution International License (CC BY). http://creativecommons.org/licenses/by/4.0/

(c) (i) Open Access

\begin{abstract}
As a sensory perception directly relating to life existence and development, the taste links to both the external reality and the people's inner spirit world as well. A Bite of China, a documentary themed delicious food, displays foods by mouthwatering screens and varied narrative techniques, which triggers the audiences' synesthesia induction from vision to taste, and even strengthens people's aesthetic perception on the yummy. This film not only encourages people to reflect their present life and survival state, but also reveals the media's profound role in shaping the cultural identity space in the modern society.
\end{abstract}

\section{Keywords}

Taste, Aesthetics, Cultural Identity, A Bite of China

\section{Introduction}

Food, the most basic element for human existence, derives from the essential desire of human beings just as a famous saying "The desire for food and sex is part of human nature" has been going since ancient times among Chinese people. Despite that people always hold a natural and sincere attitude towards foods, a series of food safety crisis this year has highlighted the survival plight of Chinese people, forcing them to reflect on their own development and existence. People's increasingly urgent desire for reliable food also enhances the strong sense of identity on the traditional, natural and reliable foods from another aspect. A Bite of China shows the director Chen Xiaoqing's identity with traditional food culture, as well as the profound thoughts on the current livelihood issues, which exactly contributes to an extensive social identity of this documentary. Carefully exploring its characteristics, we can easily find the hidden natural and timeless aesthetic connotation. Although the director 
designs it starting with the theme of food, the documentary still further opens up a broader aesthetic cognitive space, rather than simply limiting to the base of introducing all kinds of foods. By doing so, all kinds of cultures are integrated together, and broader cultural identity space is built, making it possible for all Chinese people to gain recognition on cultural values. Since a variety of narrative techniques are employed, the food cultures characterized with regions have been completely reshaped via the television image, and furthermore a contemporary Chinese food culture based on the virtual space of TV media is emerged. This is a strong evidence to prove the media technology's role in opening up the aesthetic space cognition psychology for audiences.

\section{The Sublimation for Aesthetic Space of "Taste"}

The famous German philosopher Hegel once said, "No one can really go beyond his age, just as no one exceeds his skin" (Hegel, 1983: p. 57). Though this view is the show of philosophy as spirit of the time since it coexists with a national political system, ethical life and social life, and meanwhile includes the national customs and habits, technology and material comforts, it doesn't mean only the philosophy is closely linked with the times, because literature and art also portrays the spirit of the times in its unique way. Our senses are the prime conditions for us to understand this world. It is human's sense organs and their spiritual perception that constitute our understanding on the world and identification of the culture. On this point, Marx has explicitly outlined the importance of sense organs in forming understanding, and pointed out that the formation and development of five senses perception is closely related to the whole previous human history (Marx, 1979: p. 176). A Bite of China that has touched countless Chinese taste buds and emotions ushered in a hot audience rating in May 2012. Upon released, this documentary has deeply moved the emotion and cognition towards foods in the heart of the Chinese. Exactly as what the scholar McLuhan pointed out, "Media is an extension of people", in the modern society obsessed with science and technology, electronic media has extended human's cognitive sense organs. Therefore, the cognitive ability of human being has been improved unprecedentedly, and the cognition and feeling about the world is reshaped as well. This was an unavailable understanding experience for visual and audio senses in the era of Hegel.

This food-themed documentary is totaled 7 episodes for the first series. Each episode starts with foods, which are "Gift from the Nature", "Staple Food Story", "Transformed Inspiration", "Taste of Time", "Secret of Kitchen", "Harmonious Five Flavors" and "Our Field". These topics respectively involve the sources of food, importance, preservation methods, cooking methods, food tastes and producing. Thus, deeply rooted in an agricultural nation, Chinese people emerge an emotion spiritually derived from foods and life experience, which is elaborated from the various aspects in this paper. The same as what the director Chen Xiaoqing said in the Sina interview program "Dialogue with Media Figures" column, previous food shows tended to express eating itself, eating etiquette and culture or cooking techniques, but differently, this documentary is produced with much respect and affection to the food, in order to show ordinary people's emotion for foods (Chen, 2012). Naturally, this passion for food fundamentally impresses the audiences. It sublimes the sense of beauty from physically to spiritually and also perfectly interpret the effectiveness of the audio-visual media in stimulating the audiences to obtain the aesthetic synesthesia reaction. Synesthesia means that a variety of human feelings are not completely separate, or in other words, it is a psychological phenomenon that the stimulus on a sense organ will trigger another feeling. Since born, TV media art has been widely concerned and favored by the people for its characteristics of dual stimulation on visual and audio senses. Also, it has contributed to the age of electronic media and formed synesthesia aesthetic appreciation mode. McLuhan once pointed out traditional people has accustomed to the visual experience brought by planar medium, such as printing and photo media, while TV media shows synesthetic, deep or tactile characteristics, which makes people get rid of the traditional passive and detached attitude (McLuhan, 2000: p. 415). For the food-themed documentary, synesthetic aesthetic effect of TV media seems more prominent. The strong sense of images and telling each story related to foods slowly and profoundly are alluring elements for viewer, as if they are feeling the taste through the visual perception. In traditional Chinese aesthetics, this phenomenon is summed up in a concept, that is, "taste".

"Taste", as an aesthetic concept, has double meanings in traditional Chinese aesthetics. "Taste" originally refers to the smell of natural things and taste of foods. For example, a sentence in the Zhao of Commentary of Zuo says "There are six factors in nature and five tastes" (Ruan, 2011: p. 2025). The "taste" here is the natural taste, while the aesthetic "taste" has a close relationship with sensory perception. Also in the Jinxinxia of Mencius, there is a saying goes "It is natural for mouth to enjoy taste, eye to beauty, ear to sound, nose to smell and limbs 
to comfort" (Ruan, 2011: p. 2775). Taste sense is one of the main senses of human beings and the "taste" here is used as a noun. However, the cognition of "taste" is not limited to the sensory level. Instead, the Taoist, from the perspective of philosophy, combines the "taste" with the inner feeling of subject, in which the noun "taste" referring to nature originally is considered as a verb, in order to express inner experience activities of subjects. The sixty-third chapter of Laozi says "to make a difference in an inaction attitude, to deal with things without bringing other troubles and to taste tasteless as delicious." Here the second "taste" is the noun, while the first one is a verb meaning to experience the activities. Thus, "taste" has double meanings: one is the taste of nature or food, and the other is inner disposition experience of aesthetic subjects when introduced in the literature and aesthetic experience field of art. For instance, "people are easy to get tired of gorgeous languages but plain emotions" (Liu, 1996: p. 408) by Liu Xie talks about inner experience feeling from the perspective of aesthetic subject. The connotation of "taste" gradually transforms into an aesthetic concept with double meanings with the development and maturity of aesthetic thought of Wei and Jin Dynasty. Afterwards, the concept of "taste" is constantly evolving followed by "pondering", "experiencing", "savoring" and so on. Furthermore, Chinese people's unique perception and experience on "taste" is formed. However, "experiencing" is the closest concept to Chinese aesthetic experience theory, as it contains not only the flavor and thoughts directly related to sensory experience, but also the inner disposition experience and thoughts on life existence brought by sensory feelings. "Taste" represents the formation of the ancient Chinese unique cognition in the aesthetic sense, which means the aesthetic feeling is a two-way stirring between subject and object. The aesthetic thinking that A Bite of China has is exactly the concentrated expression of aesthetic thought. When the director was interviewed, he pointed out that the documentary was named A Bite of China, as he intended to divide it into two parts: one is the taste, and the other is enabling audiences feel the changes in China through the taste (Chen, 2012). It can be said that the director has successfully expanded the aesthetic space from two aspects, making the film a visual feast that touches Chinese sense organs and also showing the Chinese aesthetic space on life.

Particularly, the director employs the most popular narrative technique in the current international documentary for the introductions of each episode, that is, the story-telling manifestation mode. Each episode is narrated focused on a theme, and both the story and food can only be enjoyed slowly, so that the deep taste can be discovered. In the Documentary also Tells Story, Sheila Curran Bernmard points out that telling a story is the key to attract audiences for most of outstanding documentaries, while a good story requires attractive figures, strong dramatic tension and convincing ending (Bernmard, 2011: p. 14). The story is bound to enhance the aesthetic expression and artistic appeal of the documentary, which can make up for the single manifestation technique caused by excessively focusing on objective representation. In the first episode themed the food source, by selecting some ways of obtaining foods, such as collecting, picking, digging and fishing, the director aims to show the close man-nature relationship emerged from the Chinese traditional farming culture. Exactly as Chen Xiaoqing says, this film is not an absolute food documentary; instead, it is a food window to show different Chinese people, the man-food and man-society relations. In this episode, the director chooses a representative food ranging from matsutake, winter bamboo shoots, and Dengs ham to lotus root and fish, which is gotten from each of obtaining way. Every kind of food is introduced from its harvest to the cooking process, and with this story recording mode, the livelihoods and lives of audiences who get these ingredients are presented. Thanks to the simple, plain and original food-making approach, the film can naturally wake up the audiences' emotion for the original food taste, as well as feelings towards natural, pure and poetic life. It is the hardship of professional lotus root-digger behind this delicious food that does impress us. So when a steaming lotus root-ribs soup appears, the audiences are instantly touched as if the tip of the tongue is savoring the tasty and also experiencing the joy of harvest. Real taste doesn't depend on an extremely food processing, but enables people to feel the most natural taste, so the director displays these favorite foods of common people with the home cooking methods. In order to collect fresh matsutake, Jane Zhoima and her daughter walk in the dense forest, following the rules in the mountain and cherishing the gift from nature. Compared with the charcoal-grilled matsutake in senior restaurants, Tibetan butter-grilled matsutake is preferable, as the film conveys a truth that only the person who understands food best knows the cooking of ingredients better. Why Dengs ham can be so well-known? It is because its seasoning is the best gift for Nuodeng endowed by the nature. Savoring tasty ham takes hard work and patience, the old Huang and his son uphold the traditional technique to refine Nuodeng salt, which endows the ham with a unique flavor. Lettuce fried ham isn't a tasty food, but when the bright ham and green lettuce are stir-fried together, the salty flavor of ham and freshness of lettuce are mixed, seemly spreading on the nose and lingering in mouth. Reviewing the whole episode, we can see the director creates a related story to ingredients 
and introduces each food cooking approach. Despite of unglamorous appearance, each food narrows the distance with audiences so that audiences in modern society seem to return back to the natural lifestyle, feel the natural taste of the food and experience the joy of harvest. "Taste", as an aesthetic category of the Chinese nation specially, is closely related to the regeneration culture of Chinese tradition. Also, it is in profound reflection and comprehension on life that Chinese people find its unique aesthetic significance.

In the highly developed society where the material wealth is greatly rich, the food is unprecedentedly meaningful, but the great satisfaction of senses fails to bring equal spiritual enrichment, the poetic sense towards life will gradually lose. How to restore the recognition and perception on the meaning of life? For this, the director selects the basic need in life and then sublimes to the identity for aesthetic demand. It can be said that the whole process of "taste" is experienced from senses to the spiritual experience, which is in line with the audience's cognitive psychology and opens up a broader cultural identity space as well.

\section{The Reshaping of Cultural Identify Space in the Era of Media}

Throughout A Bite of China, the whole documentary has broken through the framework of pure food category, because it covers a wider cultural connotation. Based on the food culture, it shows around various folk customs. Meanwhile, it is a superposition of material and non-material culture, national culture, religious ritual and ethical culture, and depicts the different regional cultures ranging from the city to the countryside, the mountain to the river and sea, as well as the grassland to basin. It covers almost every aspect of social culture. China is a country with large geographical span and diverse terrains. Geographical differences can inevitably cultivate various crops. As a traditional agricultural country, China has been taking strong reliance on nature since ancient times, thus forming different eating habits. The film, from beginning to end, is showing how people from different regions depend on the nature for survival, which demonstrates a close and harmonious Chinese-nature relationship. Thus, Chinese people are able to feel the increasingly large distance between real life and the simple traditional culture. Memory is always beautified. Over time, the disappearing tradition and the memories on the home make people feel that they have been constantly abandoned. Under high pressure, the tense and rapid modern life adds people a homeless trouble, so that they are willing to savor the home and childhood repeatedly. As Marshall Berman says, "We find ourselves basking in the environment indicating adventure, power, joy, development and self and the world is ready to change. Meanwhile, the environment will destroy all we have and we know" (Berman, 1983: p. 15). Why does A Bite of China have a unique charm of the arts? This is because it tries to restore Chinese identity on the traditional culture and construct cultural identity space by mixing multi cultures. "Media creates a new 'social group' that covers space, so other units of irrelevant areas can be gathered on TV together for a common experience, and cultural mixture is realized" (Morley \& Robbins, 2003: p. 179). A Bite of China is such a documentary that causes a viewing effect, showing the reshaping of modern global media on space. Spatial perception and cognition shaped by globalized electronic media has changed people's traditional cognition for geography and direction, and thus in some extent has evoked the hidden emotional resonance for Chinese. This emotion contains a passion for food, and a celebration for life aroused by this passion.

How does the director construct the cultural identity space? By researching on this film, we can see that the director uses the contrast interspersed among various cultures to reflect it.

1. The rural and urban are presented alternately. In the second episode, the staple food of the Chinese is introduced. Based on the food differences, it expresses the food gift given by the nature in different geographical environments. Northern Shanxi eats broom corn millet, also known as millet, and Huang Guosheng couple here who live in a cave dwelling drag yellow steamed buns made of millet to town for sell every week, but their son lives far away from the village. People in the city like to buy this handmade steamed bun with pure taste. In the modern city Ningbo, traditionally, all families would make New Year cake in the New Year. The cake making process is kept by the old in the countryside. Though little girl is making New Year cake with her great-grandmother together, it is predictable that she will only recall the taste of cake and home in the memory. People in the city are expressing the love for land and close to nature in various manners. For instance, in the last episode, Gui Chun in Beijing city develops a green space on his roof. Every Chinese city is consuming rural produced crops around, while the large city still attracts workers continually who give up farming life. This is an inevitable phenomenon in the current industrial culture and urbanization process. Contrast between urban and rural culture is presented alternately in the film. The development of urban civilization cannot cut off the Chinese taste experience formed since the agricultural era, which bridges the emotion for Chinese people.

2. Material and non-material culture, religious ritual and national culture are displayed alternately. When the 
director is introducing diet culture, he knows well that any diet must imply its nature and society causes. Therefore, he endeavors to show every food comprehensively and in details. Centered on delicacy, the film is interspersed with the material and non-material culture, making this film going beyond the mere food theme and becoming a display of Chinese poetic life. According to the definition of intangible cultural heritage, any non physical traditional culture that passes on from generation to generation includes oral traditions, folk activities and rituals and festivals, traditional performing arts, folk knowledge and practice about the nature and the universe, as well as traditional manual skills, etc. (Xin Huashe, 2011). In the fifth episode, Secret of kitchen, starting from cooking technique, introduces one of cookers that are closely bound up with "stewing", namely the Tibetan Nixi black pottery. Nixi County, Diqing Prefecture of Yunnan Province is the birthplace of nationally non-material cultural heritage, Tibetan black pottery. Also, Diqing craftsmen have inherited the traditional Tibetan pottery craft for thousands of years. Focused on diet culture, the film is added material cultures such as Nixi buildings and religious pagoda building alternately, in order to show the Tibetan lifestyle and attitude to life and further arouse the viewers' feelings and understanding on Tibetan culture. In the documentary, the director largely shows skills closely linked with food production, including Jinhua ham, fermented bean curd brewing techniques, pickles, yellow rice wine production techniques, and other intangible cultural heritage items. Since the essence and delicacy of Chinese food is inseparable from the inherited superb skill, people still can be satisfied with taste and can enjoy spiritually in the highly commercialized society. Jingjiang soup dumpling, as the traditional pastry, brings people a satisfaction of visual and taste sense with its unique flavor and translucent sensory enjoyment. The film provides a platform for soup dumpling chef Ye Jian, the non material cultural inheritor to present the food production skills. These nonmaterial cultural heritage projects are on behalf of the traditional way of life. However, with the rapid development of modern society and gradual disappearing of traditional, slow and comfortable lifestyle, the diet and cooking rooted in this lifestyle has become a rare feat. So we can also awake our identification on emotion and traditional culture when we are enjoying the food.

Another example, the scene of depicting tofu, a unique ingredient owned by the Chinese people, expresses a light flavor and nature, and also there is a saying goes that tofu-eater is content with the poor. Through narrating how vegetarian monks in Tiantai Temple meet the body needs for protein with tofu, it reveals the cultural connotation of tofu. But the film fails to fix picture on the tofu cooking techniques and skills; instead, it adds Tiantai Mountain Temple, pagoda, clock tower and other kinds of buildings from time to time when showing vegetarian culture, as well as the natural landscapes. Thus, the profound connotation between tofu and the Chinese culture is set off by contrast. The tofu with plain taste and rich nutrition exactly caters to the pursuit of religious ritual, which is also consistent with advocating the nature by traditional Chinese aesthetics. The use of this technique has deepened people's profound understanding on Chinese food culture, for food is closely linked with nation, region and religion. Based on food, a variety of material and nonmaterial cultures are able to show.

3. As a multi-ethnic country, China has a traditional diet which also contains elements of the religion and national culture. Liaoning people who live on fishing use large mesh nets to capture big fish, and meanwhile keep maintaining sustainable development and appreciating the nature. Every year in the fishing season, they will hold a grand ceremony for the fish. The ceremony is the manifestation of originally religious thinking of nature-soul since ancient time and is preserved by fishermen from generation to generation. What it reveals is the man-nature interdependence and inseparableness in traditional Chinese thought. Similarly, even in the snow covered plateau, people's diet culture still expresses gratitude for the gift of nature. Highland barley, the frost resisting plateau crop, is trusted by Tibetan, for it is not only a staple food but also an oblation to worship God. In annual barley-harvest day, people will hold a religious ceremony to thank God for feeding, and look forward to yield next year.

\section{Conclusion}

Chinese traditional food culture consists of eight cuisines with different styles, and each style has its own characteristics. This division is a reflection of regional culture, which is gradually reduced due to the modern economic globalization. As mentioned in the film, cities in China look similar. With the economic globalization trend, China's catering industry develops internationally. For instance, the internationally well-known chefs Jereme Leung mentioned in the film is rated as an outstanding one in the world, and the famous restaurant "Huangpuhui" he is operating and presiding over is named one of the world's most expensive restaurants by Forbes. It proves the development of culture industry as economy advances. Economic globalization is the best coordi- 
nation of survival factors in the world, including in trade, investment, finance and production. This means that capital and products can win more extensive market, and promote a more reasonable allocation for resources and production elements. However, everything has two sides, and globalization is not an exception as it inevitably reduces national and local characteristics. Influenced by economic globalization, science and technology is also globalized. Technology globalization is mainly realized by the global information network and the international media that promote formation of the mobile space. Thus, the narrow regional concept is facing an increasingly severe crisis. The "virtual space", determined by the satellite orbit, the network information and the wireless signal, plays a decisive significance in this era. In the era of "electronic space" of media technology globalization, the technology exerts a stronger influence on people's lifestyle than culture. Nowadays, traditional and regional culture has been impacted by foreign and modern culture, while "electronic space" under the guidance of media technology lays a foundation for the cultural identity space. The diet culture on the basis of region possesses its own distinctive features, the same as a saying "Each place has its own way of supporting its own inhabitants". As a representative of the regional culture, the diet culture is stamped with regions, including the national and geographical features. But along with the swept economic globalization, the personnel flow is expanding, and people all over the world are frequently exchanged, thus the regional diet culture is facing a tremendous impact. The real impact comes from the lifestyle choice and changes under the influence of media technology, so we can easily feel the feature of different diets with the help of media technology, and thus feel the common diet cultural identity in Chinese nation. This sense of identity is quietly advancing the cultural industry. The cultural industry has a startling power in promoting social production. After A Bite of China is broadcast, "Is it produced by Taobao" has attracted much attention and tease on the Internet. It appears to be a joke, but needs amazing data to support. According to the survey, Taobao search volume has a greatly chain growth, especially for specialty and snacks. The data show, since the documentary aired for 5 days (May 14th), a total of 5,844,791 people have searched snacks and specialty in Taobao, in which the search volume of Mao Tofu has increased the most for 48 times, while that of matsutake only improves twice. At the same time, many foodies even curiously place an order in Taobao when watching TV, such as ordering Yunnan Dengs ham. At the night of broadcasting, Taobao shop has sold a total of 32 orders of this ham, while the total shop order amounts for only 33 (Tang, 2012). This series of data implies that the film has gone beyond the category of a simple food documentary, showing the power of modern cultural industry production. By shaping the cultural identity space, indirectly making promotion for product with cultural connotation to further function on the development of social consumption, this documentary allows unacceptable traditional food suddenly becoming the hottest selling product. This effect is unexpected for the director, but is naturally within the function of modern media. Since TV media is one of the common people's favorite and the widest used media, it is crucial to consider how to give its full play in shaping cultural identity space, enriching people's spiritual life as well as promoting modern culture industry and social production. In a word, it can be said this documentary has exerted a demonstrative effect.

\section{References}

Hegel, G. W. F. (1983). A Lecture on the History of Philosophy (Volume 1). Beijing: The Commercial Press.

Marx, K. (1979). Economic and Philosophical Manuscripts of 1844. Beijing: People's Publishing House.

Chen, X. Q. (2012). Shooting a Bite of China with a Respect to Food. http://news.sina.com.cn/m/2012-05-15/095924418048.shtml

Mcluhan, M. (2000). Understanding Media: On the Extension of People. Beijing: The Commercial Press.

Ruan, Y. (2011). Thirteen Classics Exegesis. Shanghai: Shanghai Classics Publishing House.

Liu, X. (1996). Translation and Annotation of Classical Book of Literary Criticism. Jinan: Qilu Press.

Bernmard, S. C. (2011). Documentary Also Tells Story. Beijing: World Publishing Corporation.

Berman, M. (1983). All That Is Solid Melts into Air, the Experience of Modernity. London: Verso.

Morley, D., \& Robbins, K. (2003). Identity Space. Nanjing: Nanjing University Press.

Xin Huashe (2011). Intangible Cultural Heritage Law of the People's Republic of China. http://www.gov.cn/flfg/2011-02/25/content 1857449.htm

Tang, P. Y. (2012). Is A Bite of China Produced by Taobao.

http://news.ifeng.com/gundong/detail 2012 05/23/14746522 0.shtml? from ralated 


\section{Submit or recommend next manuscript to SCIRP and we will provide best service for you:}

Accepting pre-submission inquiries through Email, Facebook, LinkedIn, Twitter, etc.

A wide selection of journals (inclusive of 9 subjects, more than 200 journals)

Providing 24-hour high-quality service

User-friendly online submission system

Fair and swift peer-review system

Efficient typesetting and proofreading procedure

Display of the result of downloads and visits, as well as the number of cited articles

Maximum dissemination of your research work

Submit your manuscript at: http://papersubmission.scirp.org/ 